Case Report

\title{
Intravenous Vitamin C Administered as Adjunctive Therapy for Recurrent Acute Respiratory Distress Syndrome
}

\author{
Amit Bharara, Catherine Grossman, Daniel Grinnan, Aamer Syed, Bernard Fisher, \\ Christine DeWilde, Ramesh Natarajan, and Alpha A. (Berry) Fowler
}

Division of Pulmonary Disease and Critical Care Medicine, Department of Internal Medicine, The VCU Johnson Center for Critical Care and Pulmonary Research, Virginia Commonwealth University School of Medicine, Richmond, VA, USA

Correspondence should be addressed to Alpha A. (Berry) Fowler; alpha.fowler@vcuhealth.org

Received 14 July 2016; Accepted 11 October 2016

Academic Editor: Kenneth S. Waxman

Copyright (C) 2016 Amit Bharara et al. This is an open access article distributed under the Creative Commons Attribution License, which permits unrestricted use, distribution, and reproduction in any medium, provided the original work is properly cited.

This case report summarizes the first use of intravenous vitamin $\mathrm{C}$ employed as an adjunctive interventional agent in the therapy of recurrent acute respiratory distress syndrome (ARDS). The two episodes of ARDS occurred in a young female patient with Cronkhite-Canada syndrome, a rare, sporadically occurring, noninherited disorder that is characterized by extensive gastrointestinal polyposis and malabsorption. Prior to the episodes of sepsis, the patient was receiving nutrition via chronic hyperalimentation administered through a long-standing central venous catheter. The patient became recurrently septic with Gram positive cocci which led to two instances of ARDS. This report describes the broad-based general critical care of a septic patient with acute respiratory failure that includes fluid resuscitation, broad-spectrum antibiotics, and vasopressor support. Intravenous vitamin $\mathrm{C}$ infused at $50 \mathrm{mg}$ per kilogram body weight every 6 hours for 96 hours was incorporated as an adjunctive agent in the care of this patient. Vitamin C when used as a parenteral agent in high doses acts "pleiotropically" to attenuate proinflammatory mediator expression, to improve alveolar fluid clearance, and to act as an antioxidant.

\section{Introduction}

For many years, intensivists have searched for some agent which will attenuate the lung injury induced by the onset of pathological processes which lead to acute respiratory distress syndrome (ARDS). Thus far, following decades of research, utilizing both preclinical research employing animal model systems and clinical trials in human subjects with ARDS, no agent has been identified which attenuates ARDS-induced lung injury. Currently, ARDS continues to be associated with an approximately $25 \%$ mortality. Patients who survive ARDS often suffer long-term morbid complications from critical care support as well as posttraumatic stress disorder derived from protracted hospitalization and critical care support. In this case report, we describe the first use of intravenous vitamin $\mathrm{C}$ as an agent to attenuate sepsis-induced ARDS.

\section{Case Presentation}

31-year-old Sudanese female with a medical history of Cronkhite-Canada syndrome, a malabsorptive gastrointestinal genetic disease, who was receiving chronic hyperalimentation through a long-lasting Hickman central venous catheter, presented to the emergency department with fever (101.7 F), myalgia, and tachycardia. The patient was normotensive. Blood cultures were obtained and admission was recommended, but the patient declined admission. PA and lateral chest X-ray film was clear. No antibiotics were administered at this time (Figure 1). Forty-eight hours later, she returned to the emergency department with worsened fever and myalgia. Blood cultures returned positive for Gram positive cocci. The patient was admitted to acute care medicine but soon became hypotensive and tachycardic. She was transferred to the medical intensive care unit after 


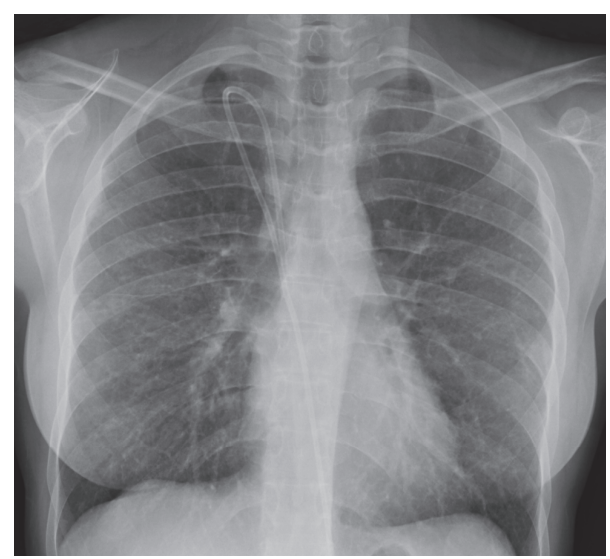

FIgURe 1

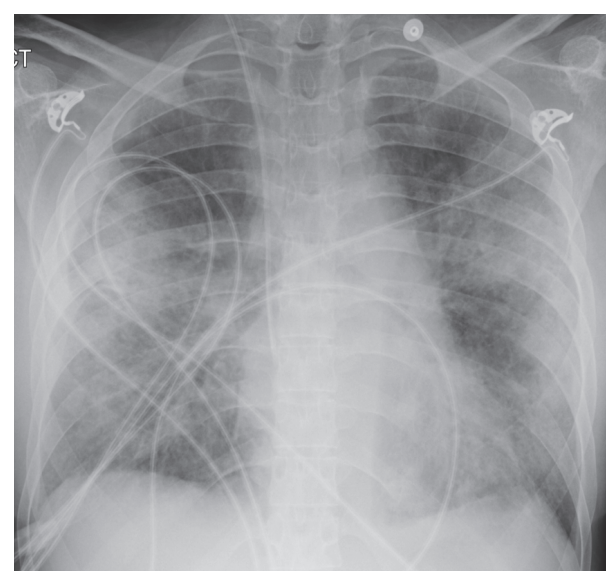

FIGURE 2

receiving four liters of intravenous volume resuscitation with $0.9 \%$ saline. Norepinephrine infusion was required and vancomycin and piperacillin/tazobactam was initiated. The patient's central venous catheter, suspected to be the source of the bacteremia, was promptly removed and a new central venous catheter placed. On hospital day 2 , the patient experienced worsened dyspnea and hypoxemia that necessitated noninvasive positive pressure ventilation (NIPPV). Repeat chest imaging revealed more remarkable opacities (Figure 2). On hospital day 3, hypoxemia and radiographic abnormalities became more significant (Figure 3 ). The patient was intubated and invasive mechanical ventilation begun for apparent sepsis-associated acute respiratory distress syndrome (ARDS). Bronchoscopy performed at this time yielded no pathogens. Low tidal volume ventilation $(6 \mathrm{cc} / \mathrm{kg}$ of ideal body weight, followed by a reduction to $4 \mathrm{cc} / \mathrm{kg}$ of ideal body weight) with high positive end expiratory pressure was initiated employing assist/control pressure/control ventilation. Despite this approach, the patient remained profoundly hypoxemic $\left(\mathrm{PaO}_{2} / \mathrm{FiO}_{2}\right.$ ratio, $\left.63 \mathrm{~mm} \mathrm{Hg}\right)$. Intravenous vitamin C (50 mg/kg every 6 hours) was initiated on hospital day 4. Chest imaging via AP chest X-ray film on hospital day 5 revealed significantly improved bilateral opacities (Figure 4).

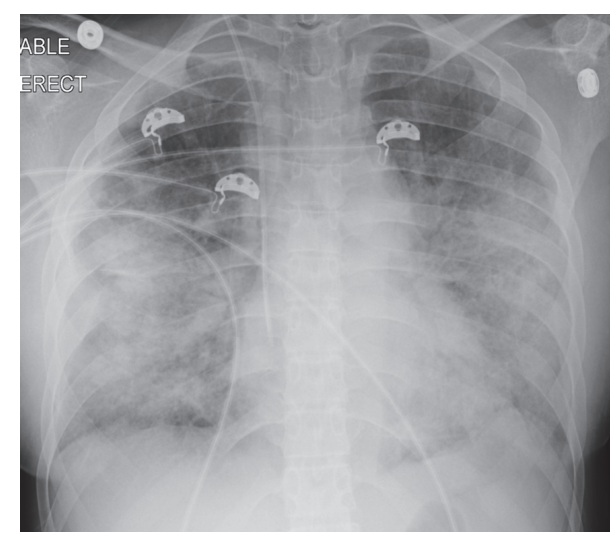

FIGURE 3

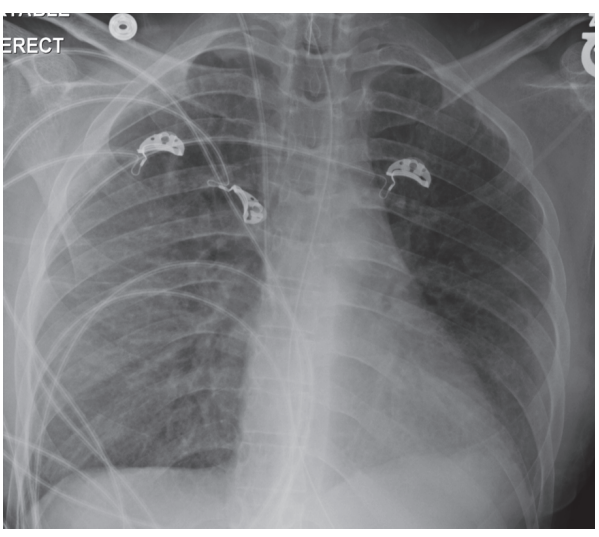

Figure 4

$\mathrm{PaO}_{2} / \mathrm{FiO}_{2}$ ratio improved significantly to $190 \mathrm{~mm} \mathrm{Hg}$. On hospital day 7 , the patient was successfully extubated.

Six weeks following initial hospitalization, the patient re-presented to the emergency department once again with headaches, fevers, and myalgia. The patient was hypotensive on admission $(62 / 37 \mathrm{~mm} \mathrm{Hg})$. Fluid resuscitation was undertaken. Hypotension persisted and she was admitted to medical ICU where she was ultimately intubated for respiratory failure. Figure 5 shows the patient's initial chest $\mathrm{X}$-ray. Despite invasive mechanical ventilation, oxygenation deteriorated and the criteria for ARDS were again met. Neuromuscular paralysis (cisatracurium) was required on ventilator day 3 due to elevated peak airway pressures and ventilator dyssynchrony. Despite this, oxygenation remained severely depressed $\left(\mathrm{PaO}_{2} / \mathrm{FiO}_{2}=100\right)$. On ventilator day 4 , intravenous vitamin $\mathrm{C}(50 \mathrm{mg} / \mathrm{kg}$ every 6 hours $)$ was initiated (Figure 6). Within two days (ventilator day 6), chest imaging dramatically improved (Figure 7) as did oxygenation $\left(\mathrm{PaO}_{2} / \mathrm{FiO}_{2}\right.$ ratio $\left.=316 \mathrm{~mm} \mathrm{Hg}\right)$. On ventilator day 10 , the patient was weaned and was successfully extubated.

\section{Discussion}

We report here the application of high dose intravenous vitamin $\mathrm{C}$ employed as an interventional drug treatment 


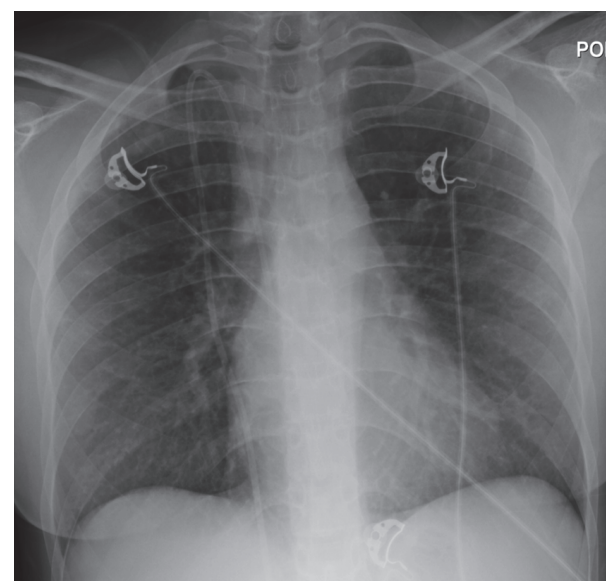

FIGURe 5

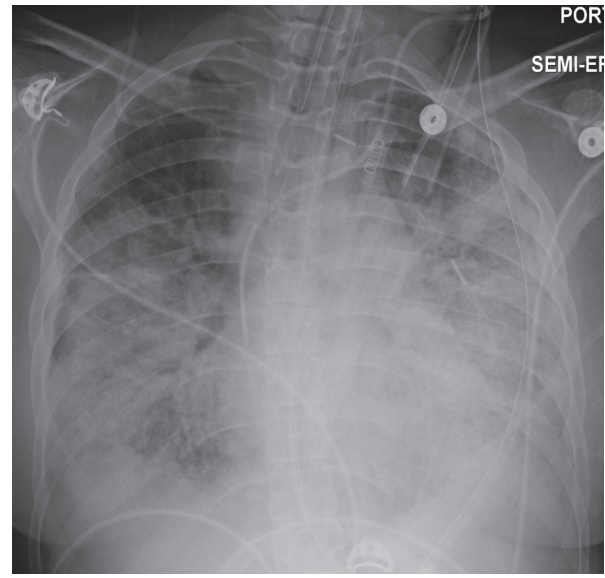

FIGURE 6

for ARDS. Very few studies in critically ill patients with ARDS have reported the use of intravenous vitamin $C$. The use of vitamin $C$ to treat lung injury is still investigational. Nathens et al. infused ascorbic acid at 1 gram every 8 hours combined with oral vitamin E for 28 days in 594 surgically critically ill patients and found a significantly lower incidence of acute lung injury and multiple organ failure [1]. Tanaka et al. infused ascorbic acid continuously at $66 \mathrm{mg} / \mathrm{kg} / \mathrm{hour}$ for the first 24 hours in patients with greater than 50\% surface area burns and showed significantly reduced burn capillary permeability [2]. A single report (published as abstract only) of a clinical study of large intravenous doses of ascorbic acid, and other antioxidants (tocopherol, $\mathrm{N}$-acetyl-cysteine, and selenium), in patients with established ARDS showed reduction in mortality of 50\% [3]. Clinical protocols currently in use for hospitalized septic patients fail to normalize ascorbic acid levels. Vitamin C dosages utilized in the treatment of the patient we describe in this case report arose from our previous human studies, infusing high dose intravenous vitamin $\mathrm{C}$ into critically ill patients with severe sepsis [4], and in our preclinical studies [5-7]. Our work thus far shows vitamin C to exert potent "pleotropic effects" when used as described in this report. We showed that septic patients receiving high

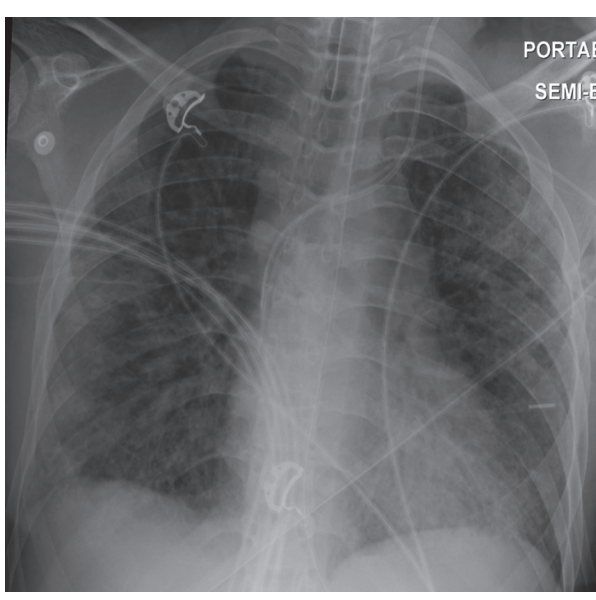

Figure 7

dose intravenous vitamin $\mathrm{C}$ exhibit significant reduction in multiple organ injury and reduced inflammatory biomarker levels [4]. Our preclinical work in septic lung-injured animals shows that vitamin $\mathrm{C}$ downregulates proinflammatory genes that are driven by transcription factor NF- $\kappa \mathrm{B}$. Furthermore, vitamin $\mathrm{C}$ significantly increases alveolar fluid clearance in septic lung-injured animals [7]. Finally, infused vitamin C's capability to downregulate liberated reactive oxygen and nitrogen species appears to be critical for attenuating lung injury [8].

\section{Competing Interests}

The authors declare that there is no conflict of interests regarding the publication of this paper.

\section{Acknowledgments}

This case report was presented at the annual international meeting of The American Thoracic Society in May of 2016. The preclinical work that led up to the use of vitamin $\mathrm{C}$ as an interventional agent in humans was supported by the Aubrey Sage McFarlane acute lung injury fund, the VCU Johnson Center for Critical Care and Pulmonary Research, and NIH/UM1 HL116885-02, Vitamin C Infusion for Treatment in Sepsis Induced Acute Lung Injury (CITRIS-ALI).

\section{References}

[1] A. B. Nathens, M. J. Neff, G. J. Jurkovich et al., "Randomized, prospective trial of antioxidant supplementation in critically III surgical patients," Annals of Surgery, vol. 236, no. 6, pp. 814-822, 2002.

[2] H. Tanaka, T. Matsuda, Y. Miyagantani, T. Yukioka, H. Matsuda, and S. Shimazaki, "Reduction of resuscitation fluid volumes in severely burned patients using ascorbic acid administration: a randomized, prospective study," Archives of Surgery, vol. 135, no. 3, pp. 326-331, 2000.

[3] M. A. J. Sawyer, J. J. Mike, and K. Chavin, "Antioxidant therapy and survival in ARDS," Critical Care Medicine, vol. 17, article S153, 1989. 
[4] A. A. Fowler III, A. A. Syed, S. Knowlson et al., "Phase I safety trial of intravenous ascorbic acid in patients with severe sepsis," Journal of Translational Medicine, vol. 12, article 32, 2014.

[5] B. J. Fisher, I. M. Seropian, D. Kraskauskas et al., "Ascorbic acid attenuates lipopolysaccharide-induced acute lung injury," Critical Care Medicine, vol. 39, no. 6, pp. 1454-1460, 2011.

[6] B. J. Fisher, D. Kraskauskas, E. J. Martin et al., "Attenuation of sepsis-induced organ injury in mice by vitamin C," Journal of Parenteral and Enteral Nutrition, vol. 38, no. 7, pp. 825-839, 2014.

[7] B. J. Fisher, D. Kraskauskas, E. J. Martin et al., "Mechanisms of attenuation of abdominal sepsis induced acute lung injury by ascorbic acid," American Journal of Physiology-Lung Cellular and Molecular Physiology, vol. 303, no. 1, pp. L20-L32, 2012.

[8] M. M. Berger and H. M. Oudemans-van Straaten, "Vitamin C supplementation in the critically ill patient," Current Opinion in Clinical Nutrition and Metabolic Care, vol. 18, no. 2, pp. 193-201, 2015. 


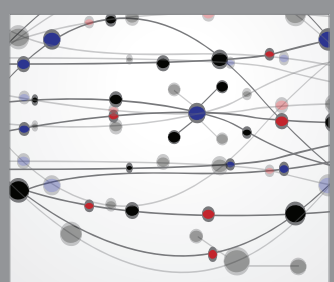

The Scientific World Journal
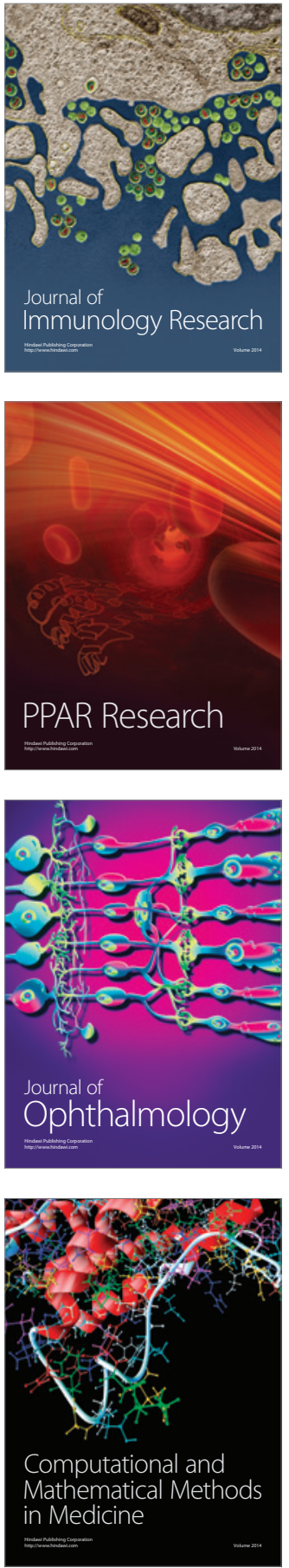

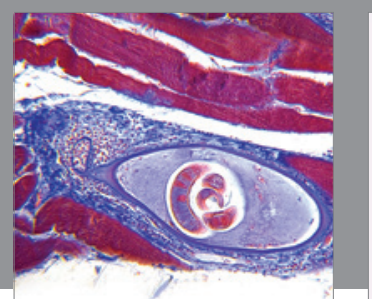

Gastroenterology Research and Practice

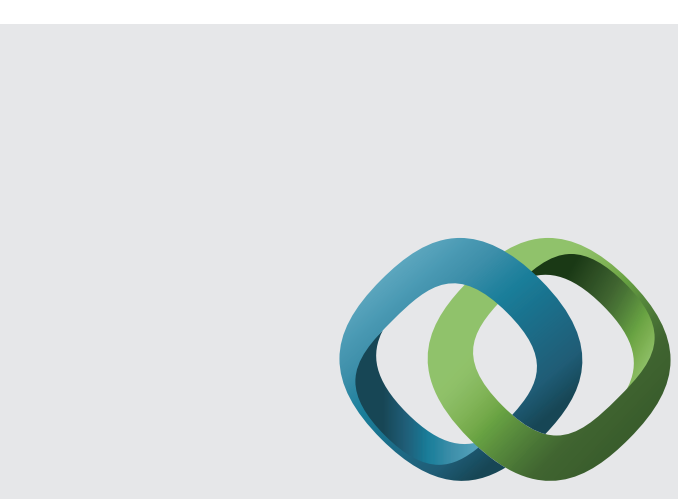

\section{Hindawi}

Submit your manuscripts at

http://www.hindawi.com
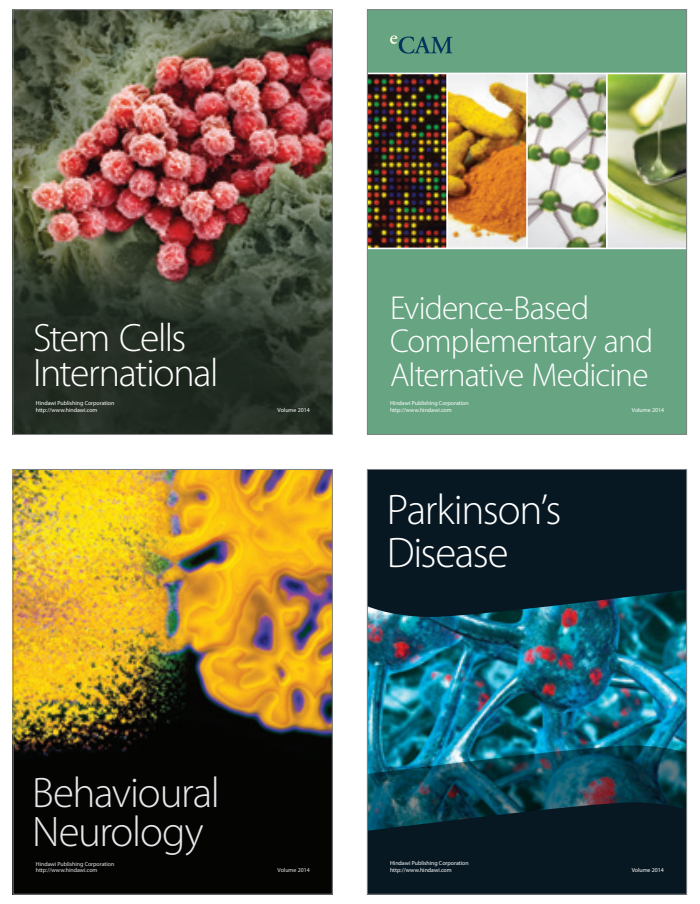
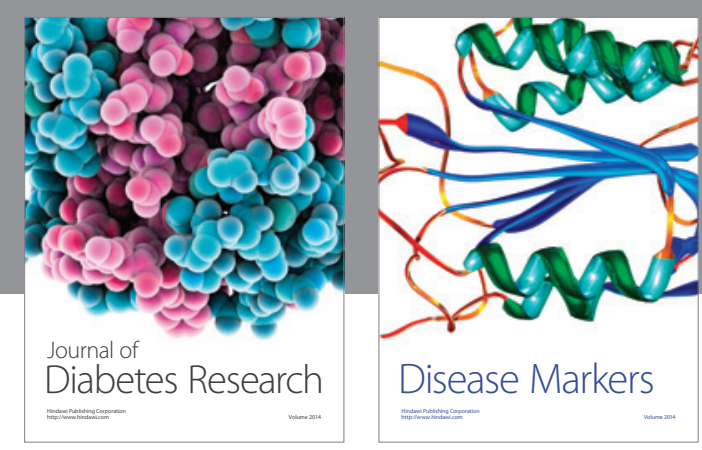

Disease Markers
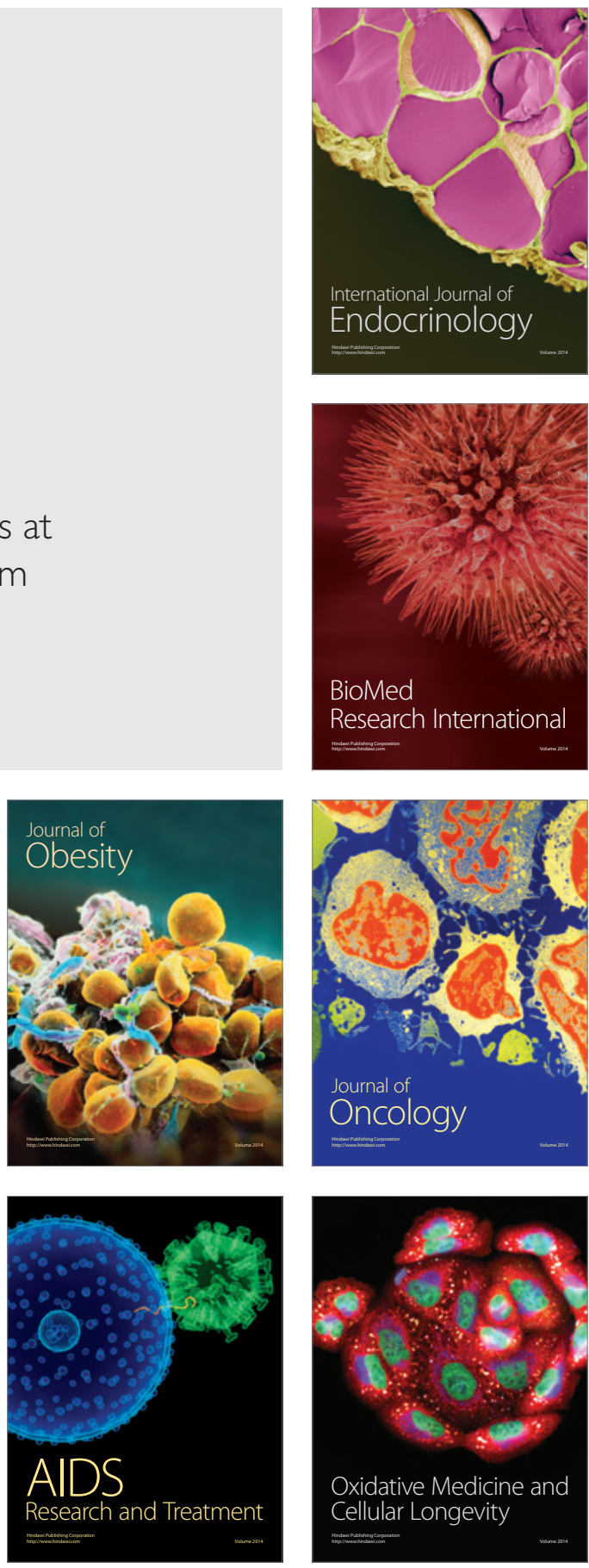